\title{
Job insecurity and incident coronary heart disease: the Whitehall II prospective cohort study
}

\author{
Jane E Ferrie ${ }^{1,2}$, Mika Kivimäki ${ }^{2,3}$, Martin J Shipley ${ }^{2}$, George Davey Smith ${ }^{1,4}$, and Marianna \\ Virtanen ${ }^{3}$
}

${ }^{1}$ School of Social and Community Medicine, University of Bristol, UK ${ }^{2}$ Department of Epidemiology and Public Health, University College London, London, UK ${ }^{3}$ Finnish Institute of Occupational Health, Helsinki, Finland ${ }^{4} \mathrm{MRC}$ Centre for Causal Analyses in Translational Epidemiology, University of Bristol, UK

\section{Abstract \\ Objective-This study uses a prospective design to examine the association between self- reported job insecurity and incident coronary heart disease; an association which has been little investigated previously.}

Methods-Participants were 4174 British civil servants (1236 women and 2938 men), aged 42 to 56 with self-reported data on job insecurity and free from coronary heart disease at baseline (1995-6). These participants were followed until 2002-4, an average of 8.6 years, for incident fatal coronary heart disease, clinically verified incident non-fatal myocardial infarction, or definite angina (a total of 168 events).

Results-Cox proportional hazard models adjusted for socio-demographic characteristics showed job insecurity to be associated with a 1.42-fold (95\% CI, 1.05-1.93) risk of incident coronary heart disease compared with secure employment. Adjustment for physiological and behavioral cardiovascular risk factors had little effect on this estimate; 1.38 (1.01-1.88).

Conclusion-This study suggests that job insecurity may adversely affect coronary health.

\section{Keywords \\ job insecurity; stress; incident coronary heart disease; angina; middle-aged; prospective}

\section{Introduction}

In the UK the government plans to cut 880,000 public-sector jobs by 2017.[1] Economic crises across Europe in the wake of the banking crisis and ongoing high levels of job insecurity and unemployment in the US indicate that this is not a problem limited to the UK. With knock on effects on local economies and further job losses in those sections of the

(C) 2012 Elsevier Ireland Ltd. All rights reserved.

Author for correspondence Dr Jane Ferrie, Senior Research Fellow, School of Social and Community Medicine, University of Bristol, Oakfield House, Oakfield Road, Bristol BS8 2BN, UK, telephone (+44) 117331 0052, jane.ferrie@ucl.ac.uk.

Institution at which work was performed: Department of Epidemiology and Public Health, University College London Medical School, UK

Publisher's Disclaimer: This is a PDF file of an unedited manuscript that has been accepted for publication. As a service to our customers we are providing this early version of the manuscript. The manuscript will undergo copyediting, typesetting, and review of the resulting proof before it is published in its final citable form. Please note that during the production process errors may be discovered which could affect the content, and all legal disclaimers that apply to the journal pertain. 
private sector dependent on public sector money, many workers are experiencing a high degree of job insecurity.

Evidence strongly suggests that unemployment is associated with increased physical and psychological morbidity and increased mortality.[2,3] However, evidence of a link between job insecurity, or the threat of unemployment, and health outcomes, with the exception of psychological well-being and some self-reported health outcomes, [4-8] remains very limited. Given that self-reported job insecurity is a strong psychosocial stressor,[9] surprising little work has examined its association with coronary heart disease (CHD), the classic objective health outcome in much stress-related research. [10]

The three population studies to date have produced mixed findings. A study in men provided no evidence of an association between self-reported job insecurity and ischemic heart disease after adjustment for somatic and behavioral coronary risk factors.[11] After similar adjustment, a study in 36,910 women did show an association between self-reported job insecurity and non-fatal myocardial infarction (MI), but no association with total CHD or fatal CHD over a 2-year follow-up, or with any outcome after 4 years.[12] Lastly, an association between self-reported job insecurity and cardiovascular disease observed in analyses adjusted for age, race and randomization among 22,086 women in an aspirin and Vitamin E placebo-controlled trial was attenuated on adjustment for education and income. [13] To address this equivocal evidence we undertook a prospective analysis of self-reported job insecurity and incident CHD in a cohort of white-collar workers, approximately twothirds men.

\section{Methods}

\section{Study population}

The target population for the Whitehall II study was all London-based office staff aged 35-55 in 20 civil service departments in 1985. Of these, 10,308 enrolled; a response rate of 73\%. Data collection at enrolment, Phase 1 (1985-1988) involved a clinical examination, which obtained physiological measures, and a self-administered questionnaire covering socio-economic factors, health, work and lifestyle. Subsequent data collection phases have alternated between a questionnaire (even-numbered phases), and questionnaire plus clinical examination (odd-numbered phases).[14] This study uses data from Phase 4 (1995-1996) when participants were aged 42-56 and self-reported job insecurity was included for the first time.

\section{Exposure, outcome and covariates}

Self-reported job insecurity was measured using the question 'How secure is your present job?' Response categories 'Very insecure' and 'Insecure' were collapsed to form the 'insecure' exposure group and 'Very secure' and 'Secure' to form the reference group. Follow-up of incident fatal CHD, clinically verified incident non-fatal myocardial infarction, or definite angina until Phase 7 (2002-2004) provided a mean follow-up for CHD events of 8.6 years (S.D. 1.9). Incident CHD comprised coronary death, first non-fatal MI, or first definite angina. The British National Health Service Central Registry provided information regarding the date and cause of all deaths. These deaths were classified as coronary either if International Classification of Diseases Ninth Revision (ICD9) codes 410 to 414, or ICD10 codes I20 to I25, were cited on the death certificate. Non-fatal MI was defined using the WHO MONICA Project criteria [15] and ascertained using data from Whitehall II study resting electrocardiograms (ECGs) recorded every 5 years; and ECGs and cardiac enzyme levels obtained from records during hospitalisation for acute myocardial infarction. Definite angina was defined by clinical records, abnormalities on ECG or coronary angiogram, and 
nitrate medication use, but excluded self-reports not clinically verified. [16] Two trained experts classified cardiac events and reached agreement on inconsistencies. Covariates included age, sex, marital status, occupational grade level, and prevalent diabetes (measured at Phase 4); systolic and diastolic blood pressure, cholesterol and body mass index (BMI), smoking, alcohol consumption, daily fruit and vegetable use, hours/week of moderate or vigorous exercise (measured at Phase 3, 1991-1994).[14] The role of mental health in the association between job insecurity and CHD was examined using the SF-36 mental health score (a 5-item scale assessing psychological wellbeing).[17]

\section{Sample selection}

Out of the 5411 participants still employed by the Civil Service at Phase 4, 4922 responded to the question on self-reported job insecurity. Of these, 4316 had complete data for the covariates. Removal of 142 participants with prevalent CHD left 4174 participants in the analyses.

\section{Statistical analysis}

Associations between self-reported job insecurity and baseline characteristics were examined using a chi-squared test for heterogeneity. For continuous measures, differences between insecure and secure groups were assessed using univariate analysis of variance. After confirmation that the proportional hazards assumption were met (time-dependent interaction term between job insecurity and log of the follow-up period for CHD was nonsignificant $\mathrm{p}=0.49$ ), Cox proportional hazard models with follow-up period as the time scale were used to examine the association between job insecurity and incident CHD. Secure employees formed the reference category used to calculate hazard ratios and their $95 \%$ confidence intervals. Models were serially adjusted for covariates to examine whether they affected the association. As there was no interaction between sex and job insecurity in relation to $\mathrm{CHD}(p=0.17)$, women and men were combined.

\section{Results}

Forty percent of participants reported that their job was insecure.Table 1 presents the distribution of baseline covariates by self-reported job security. Insecure participants were slightly younger than secure participants, more likely to be lower in the occupational hierarchy and have a higher BMI, and less likely to eat fruit and vegetables daily. Otherwise, self-reported job security was evenly distributed across the covariates measured. Table 2 shows the association between self-reported job insecurity and incident CHD. Altogether there were 35,896 person-years of follow-up during which 168 new CHD events occurred over 8.6 years, an event rate of 4.7/1000 person-years. In the age-adjusted model (Model 1), job insecurity was associated with incident CHD HR 1.41, (95\% CI 1.04-1.91), compared to secure employment. Cumulative additional adjustment for socioeconomic factors (Model 2), physiological measures (Model 3) and behavioral factors (Model 4) had little effect on this association HR 1.38, 95\% CI 1.01-1.88 (Model 4). To examine whether mental health is a potential mediator of any association between job insecurity and CHD, we compared the SF-36 mental health score between participants in insecure and secure jobs. SF36 scores among the insecure indicated poorer mental health in this group (mean 68.5 vs. 76.3, $\mathrm{P}<0.001$ ). Adjustment for the SF-36 mental health score further attenuated the association between job insecurity and CHD (HR 1.26, 95\% CI 0.91-1.73) (Model 5).

\section{Discussion}

This prospective study provides evidence that self-reported job insecurity is associated with a $40 \%$ excess risk of new-onset coronary heart disease. This association was also observed 
after taking account of socioeconomic factors and other well-known major risk factors for heart disease. Our finding stands in contrast to previous studies of self-reported job insecurity and CHD which have provided little evidence of an association in either sex. [11-13] On the other hand, the size of the effect observed is identical to that for other workbased psychosocial stressors, such as job strain, where a $40 \%$ excess in incident coronary events has been reported in the most recent meta-analyses of published studies.[18] It is possible of course that the association between job insecurity and coronary heart disease may be mediated through other stressful work characteristics, such as job strain. In an earlier report from the Whitehall II study, perceived job insecurity was associated with low decision latitude, low skill discretion, high job demands (in women), low social support at work, and low job satisfaction.[19] Further research using repeat measurements of work characteristics is needed to examine whether work characteristics act as mediators or as confounders of the job insecurity-CHD association. Our examination of the role of mental health in the association between job insecurity and CHD found a degree of attenuation after adjustment for SF-36 mental health score. This finding is consistent with the role of mental health as a confounder of the association between job insecurity and CHD but does not preclude the notion that job insecurity may adversely affect mental health which, in turn, is associated with increased coronary disease risk.

A limitation in our data was reliance on a heterogeneous CHD endpoint, which included self-reported angina. Re-running the analyses separately for definite angina and fatal CHD/ non-fatal MI gave a hazard ratio of $1.46(1.02-2.08)$ for the association between job insecurity and angina in the fully adjusted model. The corresponding hazard ratio for fatal CHD and non-fatal MI as an outcome was 1.40 (0.86-2.27). Thus the magnitude of the effect was similar in both analyses, but the latter analysis, with only 68 events, lacked statistical power. All self-reported instances of angina were confirmed clinically. While some misclassification due to undiagnosed angina is possible, previous studies have shown angina to be a strong predictor of future cardiovascular events.[20,21] Larger studies that can examine more specific CHD endpoints, such as fatal and non-fatal myocardial infarction, stable and non-stable angina, and first myocardial infarction with and without the ST segment on ECG (STEMI and non-STEMI) are needed to provide a more nuanced understanding of the potential adverse consequences of job insecurity for heart health. [22-25]

Sample attrition between recruitment (1985-1988) and baseline for the present study (1995-1996) may have introduced non-response bias, as non-response has been associated with increased mortality in the Whitehall II study.[26] Certainly there were differences between the Whitehall II baseline population (67\% men, 23\% in the lowest occupational grade) and the sample used in the present analyses ( $70 \%$ men, $14 \%$ in the lowest occupational grade). However, as non-response is more likely among those in insecure rather than secure employment, the observed associations might, if anything, underestimate the job insecurity-CHD relation.

Other limitations of this study which should be noted when interpreting the results are; unmeasured or imprecisely measured risk factors that may result in residual confounding; a single measure of job insecurity at baseline will not capture ongoing exposure; covariates modeled as time independent may change over the follow-up period; and findings from a white-collar cohort may not be generalisable to blue-collar workers and private sector employees. These limitations are counterbalanced by important strengths; a prospective design, large population including both sexes, clinically verified event data, and a suitable follow-up period. 


\section{Acknowledgments}

The Whitehall II study is supported by grants from the Medical Research Council; British Heart Foundation; Health and Safety Executive; Department of Health; National Heart Lung and Blood Institute (HL36310) National Institute on Aging (AG13196 and AG34454); Agency for Health Care Policy Research (HS06516); and the BUPA

Foundation. MK is supported by the Academy of Finland, the EU New OSH ERA Research Programme and a professorial fellowship from the Economic and Social Research Council, UK, MJS by the British Heart Foundation and MV by Academy of Finland Project 258598.

Financial support: Please see Acknowledgements

\section{References}

1. Stewart H. Public sector workforce 'will shrink to record low by 2017'. The Observer. 2012 Mar 25.

2. Roelfs DJ, Shor E, Davidson KW, et al. Losing life and livelihood: a systematic review and metaanalysis of unemployment and all-cause mortality. Soc Sci Med. 2011; 72:840-854. [PubMed: 21330027]

3. Mathers CD, Schofield DJ. The health consequences of unemployment: the evidence. Med J Aust. 1998; 168:178-182. [PubMed: 9507716]

4. Sverke M, Hellgren J, Naswall K. No security: a meta-analysis and review of job insecurity and its consequences. J Occup Health Psychol. 2002; 7:242-264. [PubMed: 12148956]

5. Ferrie, JE.; Martikainen, P. The Heath Effects of a Psychosocial Work Stressor. In: Fink, G., editor. Encyclopaedia of Stress. 2. Oxford: Academic Press; 2007. p. 549-555.

6. Laszlo KD, Pikhart H, Kopp MS, Bobak M, Pajak A, Malyutina S, et al. Job insecurity and health: a study of 16 European countries. Social science \& medicine. 2010; 70:867-74. [PubMed: 20060634]

7. Cheng GHL, Chan DKS. Who suffers more from job insecurity? A meta-analytic review insecurity? A meta-analytic review. 2008; 57:272-303.

8. Quinlan M, Bohle P. Overstretched and unreciprocated commitment: reviewing research on the occupational health and safety effects of downsizing and job insecurity. International journal of health services. 2009; 39:1-44. [PubMed: 19326777]

9. Lazarus, RS.; Folkman, S. Stress, Appraisal, and Coping. New York: Springer; 1984.

10. Stansfeld, SA.; Marmot, MG. Stress and the Heart: Psychosocial Pathways to Coronary Heart Disease. London: BMJ Books; 2001.

11. Siegrist J, Peter R, Junge A, et al. Low status control, high effort at work and ischemic heart disease: Prospective evidence from blue-collar men. Soc Sci Med. 1990; 31:1127-1134. [PubMed: 2274801]

12. Lee S, Colditz GA, Berkman LF, et al. Prospective study of job insecurity and coronary heart disease in US women. Ann Epidemiol. 2004:24-30. [PubMed: 14664776]

13. Slopen N, Glynn RJ, Buring JE, et al. Job Insecurity, and Incident Cardiovascular Disease in the Women's Health Study:Results from a 10-year Prospective Study. Plos One. 2012; 7:e40512. [PubMed: 22815754]

14. Marmot M, Brunner E. Cohort Profile: the Whitehall II study. Int J Epidemiol. 2005; 34:251-6. [PubMed: 15576467]

15. Tunstall-Pedoe H, Kuulasmaa K, Amouyel P, Arveiler D, Rajakangas AM, Pajak A. Myocardial infarction and coronary deaths in the World Health Organization MONICA Project. Registration procedures, event rates, and case-fatality rates in 38 populations from 21 countries in four continents. Circulation. 1994; 90:583-612. [PubMed: 8026046]

16. Rose, GA.; Blackburn, H.; Gillum, RF.; Prineas, RJ. Cardiovascular Survey Methods. 2. Geneva: World Health Organization;

17. Ware, JE.; Kosinski, M.; Keller, SD. SF-36 physical and mental health summary scales: A user manual. Massachusetts: The Health Institute, New England Medical Center; 1994.

18. Kivimaki M, Nyberg S, Batty GD, Fransson EI, Heikkila K, Alfredsson L, et al. Job strain as a risk factor for coronary heart disease: a collaborative meta-analysis of individual participant data. Lancet. 2012 Sep 13.10.1016/S0140-6736(12)60994-5 
19. Ferrie JE, Shipley MJ, Newman K, Stansfeld SA, Marmot M. Self-reported job insecurity and health in the Whitehall II study: potential explanations of the relationship. Soc Sci Med. 2005; 60:1593-602. [PubMed: 15652690]

20. Hemingway H, McCallum A, Shipley M, Manderbacka K, Martikainen P, Keskimaki I. Incidence and prognostic implications of stable angina pectoris among women and men. JAMA. 2006:14041411. [PubMed: 16551712]

21. Murphy NF, Stewart S, Hart CL, MacIntyre K, Hole D, McMurray JJ. A population study of the longterm consequences of Rose angina: 20-year follow-up of the Renfrew-Paisley study. Heart. 2006; 92:1739-1746. [PubMed: 16807274]

22. Cannon, CP.; Braunwald, E. The spectrum of myocardial ischaemia: the paradigm of acute coronary syndromes. In: Cannon, CP., editor. Management of acute coronary syndrome. Human Press; 2003.

23. Terkelsen CJ, Lassen JF, Norgaard BL, et al. Mortality rates in patients with ST-elevation vs. nonSTelevation acute myocardial infarction: observations from an unselected cohort. Eur Heart J. 2005; 26:18-26. [PubMed: 15615795]

24. Abbott JD, Ahmed HN, Vlachos HA, et al. Comparison of outcome in patients with ST-elevation versus non-ST-elevation acute myocardial infarction treated with percutaneous coronary intervention (from the National Heart, Lung, and Blood Institute Dynamic Registry). Am J Cardiol. 2007; 100:190-195. [PubMed: 17631068]

25. Samani NJ, Erdmann J, Hall AS, et al. Genomewide association analysis of coronary artery disease. N Engl J Med. 2007; 357:443-453. [PubMed: 17634449]

26. Ferrie JE, Kivimäki M, Singh-Manoux A, Shortt A, Martikainen P, Head J, Marmot M, Gimeno D, De Vogli R, Elovainio M, Shipley MJ. Non-response to baseline, non-response to follow-up and mortality in the Whitehall II cohort. Int J Epidemiol. 2008; 38:831-7. [PubMed: 19264846]

\section{Abbreviations}

$\begin{array}{ll}\text { BP } & \text { Blood Pressure } \\ \text { CI } & \text { Confidence Interval } \\ \text { CHD } & \text { Coronary Heart Disease } \\ \text { HR } & \text { Hazard Ratio } \\ \text { MI } & \text { Myocardial Infarction }\end{array}$


Table 1

\section{Characteristics of the participants by self-reported job insecurity at baseline}

\begin{tabular}{|c|c|c|c|c|}
\hline \multirow{2}{*}{ Characteristics } & \multirow[b]{2}{*}{ All $(n=4,174)$} & \multicolumn{3}{|c|}{ Job insecurity at baseline } \\
\hline & & Secure $(n=2,506)$ & Insecure $(1,668)$ & $P$-value* \\
\hline Age (years), Mean (S.D.) & $50.3(4.9)$ & $50.5(5.1)$ & $50.1(4.7)$ & 0.009 \\
\hline Sex, (n \%) & & & & 0.10 \\
\hline Men & $2,938(70)$ & $1,788(71)$ & $1,150(69)$ & \\
\hline Women & $1,236(30)$ & $718(29)$ & $518(31)$ & \\
\hline Marital status, (n \%) & & & & 0.27 \\
\hline Married/cohabiting & $3,254(79)$ & $1,968(79)$ & $1,286(77)$ & \\
\hline Non-married/cohabiting & $920(21)$ & $538(21)$ & $382(23)$ & \\
\hline Occupational grade level, (n \%) & & & & $<0.001$ \\
\hline I highest & $789(19)$ & $514(21)$ & $275(16)$ & \\
\hline II & $924(22)$ & $597(24)$ & $327(20)$ & \\
\hline III & $591(14)$ & $345(14)$ & $246(15)$ & \\
\hline IV & $699(17)$ & $395(16)$ & $304(18)$ & \\
\hline $\mathrm{V}$ & $567(14)$ & $302(12)$ & $265(16)$ & \\
\hline VI lowest & $604(14)$ & $353(14)$ & $251(15)$ & \\
\hline Prevalent diabetes, (n \%) & & & & 0.89 \\
\hline No & $4,095(98)$ & $2,458(98)$ & $1,637(98)$ & \\
\hline Yes & $79(2)$ & $48(2)$ & $31(2)$ & \\
\hline Systolic BP ${ }^{* *}(\mathrm{mmHg})$, Mean (S.D.) & $119.5(12.9)$ & $119.6(12.9)$ & $119.2(13.0)$ & 0.31 \\
\hline Diastolic BP (mmHg), Mean (S.D.) & $79.2(9.1)$ & $79.3(9.2)$ & $79.1(9.1)$ & 0.60 \\
\hline Cholesterol (mmol/L), Mean (S.D.) & $6.4(1.2)$ & $6.4(1.1)$ & $6.4(1.2)$ & 0.47 \\
\hline Body mass index $\left(\mathrm{kg} / \mathrm{m}^{2}\right)$, Mean (S.D.) & $25.0(3.6)$ & $24.9(3.6)$ & $25.2(3.7)$ & 0.010 \\
\hline Smoking, (n \%) & & & & 0.33 \\
\hline Never & $2,209(53)$ & $1,343(54)$ & $866(52)$ & \\
\hline Ex & $1,412(34)$ & $846(34)$ & $566(34)$ & \\
\hline Current & $553(13)$ & $317(13)$ & $236(14)$ & \\
\hline Alcohol use (units/week), (n \%) & & & & 0.08 \\
\hline 0 & $745(18)$ & 420 (17) & $325(19)$ & \\
\hline $0-14$ (women)/-21 (men) & $2,706(65)$ & $1648(66)$ & $1058(63)$ & \\
\hline$>14 / 21$ & $723(17)$ & $438(17)$ & $285(17)$ & \\
\hline Daily fruit and vegetable use & & & & 0.002 \\
\hline Yes & $2,566(61)$ & $1,588(63)$ & $978(59)$ & \\
\hline No & $1,608(39)$ & $918(37)$ & $690(41)$ & \\
\hline Moderate/vigorous exercise (hrs/week) & & & & 0.95 \\
\hline$<1.5$ & $1,359(33)$ & $815(33)$ & $544(33)$ & \\
\hline$\geq 1.5$ & 2,815 (67) & $1,691(67)$ & $1,124(67)$ & \\
\hline
\end{tabular}

Atherosclerosis. Author manuscript; available in PMC 2014 March 03. 


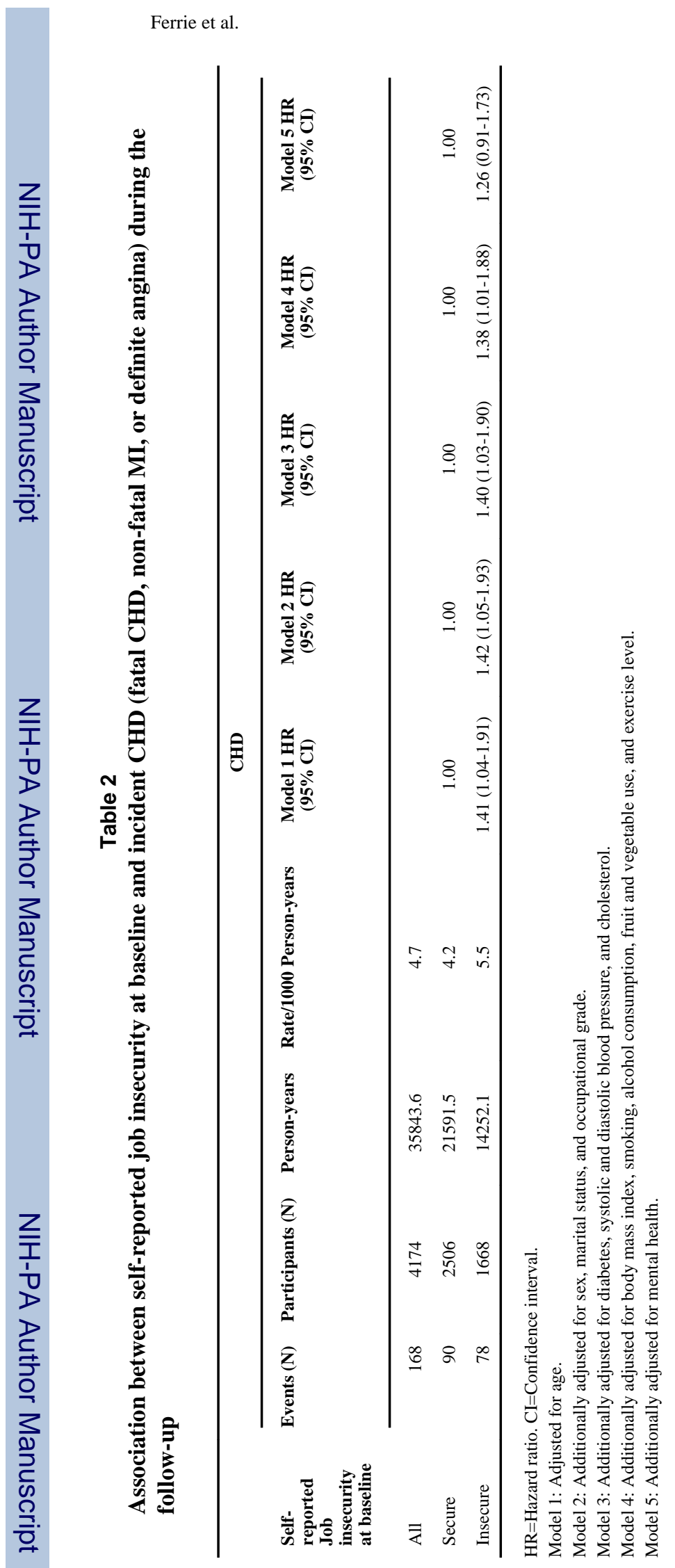

Atherosclerosis. Author manuscript; available in PMC 2014 March 03. 